\title{
ТЕХНИКА УСТАНОВЛЕНИЯ, ПРЕОДОЛЕНИЯ И УСТРАНЕНИЯ ПРАВОТВОРЧЕСКИХ ОШИБОК КАК ПРОЯВЛЕНИЕ КУЛЬТУРЫ ЗАКОНОТВОРЧЕСТВА
}

\author{
Баранов В.М., Лаврентьев А.P.
}

Аннотация: Культура законотворчества имманентно отражает уровень культуры в соответствующем обществе. Соответственно, культура законотворчества предполагает несколько взаимосвязанных аспектов изучения: определенный результат развития культуры общества на данном этапе; форма человеческой деятельности в области правотворчества; показатель уровня правовой культуры общества. Одним из проявлений культуры законотворчества, на наш взгляд, выступает работа «над ошибками». Как и любой вид человеческой деятельности, законотворчество не свободно от недостатков, некоторые из которых можно отнести к очибкам - непреднамеренным отклонениям от правильных действий, поступков и мыслей, которые приводят к разнице между ожидаемой или измеренной и реальной величиной. Метод или методология исследования: диалектика, абстрагирование, анализ, синтез, дедукция, формально-юридический метод, метод межотраслевых юридических исследований. В последнее время четко наметилось несколько тендениий систематизации в российском законодательстве. При этом общая концепция систематизации не регламентирована и можно рассуждать о формах, видах, содержании и иных ее элементах.Научная и практическая значимость. Проведенное исследование развивает и уточняет общую теорию права, теорию реконструкиии законодательных ошибок и методологию их преодоления на основе постоянного повышения уровня культуры, включая культуру законодателя.

Ключевые слова: Предупреждение, преступность, профилактика, критерий, пресечение, вред, уровень преступности, борьба, индивидуальное, статистические данные. 
Культура законотворчества имманентно отражает уровень культуры в соответствующем обществе. Культура законотворчества предполагает несколько взаимосвязанных аспектов изучения: определенный результат развития культуры общества на данном этапе; форма человеческой деятельности в области правотворчества; показатель уровня правовой культуры общества.

Понятие «культура» раскрывается в Основах государственной культурной политики [1] как «совокупность формальных и неформальных институтов, явлений и факторов, влияющих на сохранение, производство, трансляцию и распространение духовных ценностей (этических, эстетических, интеллектуальных, гражданских и т. д.)». Нормативное понятие охватывает только одну сторону понятия «культура», но предполагает несколько вариантов интерпретации (от лат. cultura - возделывание, обрабатывание; поклонение, почитание; воспитание, образование, развитие). Для целей нашего исследования, помимо нормативного определения, наиболее уместны такие вариации понятия «культура»:

- «исторически определенный уровень развития общества, творческих сил и способностей человека, выраженный в типах и формах организации жизни и деятельности людей, в их взаимоотношениях, а также в создаваемых ими материальных и духовных ценностей» [2] или, намного лаконичнее: «совокупность достижений человеческого общества в производственной, общественной и духовной жизни» [3];
- «человеческие силы и способности, реализуемые в деятельности: знания, умения, навыки, уровень интеллекта, нравственного и эстетического развития, мировоззрение, способы и формы общения людей» [4];

- «высокий уровень развития какой-либо сферы человеческой деятельности или условий его жизни» [5].

Одним из проявлений культуры законотворчества, на наш взгляд, выступает работа «над ошибками». Как и любой вид человеческой деятельности, законотворчество не свободно от недостатков, некоторые из которых можно отнести к ошибкам - непреднамеренным отклонениям от правильных действий, поступков и мыслей, которые приводят к разнице между ожидаемой или измеренной и реальной величиной. Законодательные ошибки могут быть рассмотрены как в теоретическом ключе (теория законодательных ошибок), так и в прикладном (техника установления, преодоления и устранения).

Раскрытие этой высокоценной проблемы значительно облегчается тем, что авторы настоящей работы в мае 2008 г. провели Международный научно-практический круглый стол, материалы которого были опубликованы в сборнике объемом более 1000 страниц [6]. Многие предложения и рекомендации участников форума не потеряли своей актуальности до сих пор.

Выход в 2016 году ежегодника «Юридическая техника» оказался своеобразной конкретизацией функционирования выявленного негативного пласта законотворчества в сфере культуры [7]. Культура - ценностный 
вектор выявления общих и частных, типичных и экзотических дефектов законотворчества, катализатор преодоления их вредных последствий.

Теория законодательных ошибок формировалась на основе собственно юридических знаний общетеоретического и отраслевого характера, а также в результате междисциплинарных исследований, в том числе зарубежного опыта.

Детальному анализу подвергнуты проблемы разграничения ошибок в различных видах юридической деятельности: правообразовании [8], правотворчестве [9] и законотворчестве [10] (в том числе особенности законотворческих ошибок на различных стадиях законотворчества - проектирования правовых норм, [11] опубликования правовых норм [12] - и в различных отраслях права [13]), интерпретации [14] правовых норм и правоприменении [15]. Изучены различные виды законодательных ошибок: пробелов [16] коллизий [17] и иных дефектов [18].

Разумеется, теория законодательных ошибок продолжает развиваться, причем как по направлениям, относительно легко прогнозируемым вследствие специализации научного познания - изучаются особенности отдельных видов ошибок в различных отраслях права, так и в неожиданных ракурсах: поиски причин и условий ошибочной деятельности [19，，выявление особенностей ошибок как юридических дефектов [20], специфика правотворческих ошибок органов государственной власти субъектов Российской Федерации и органов местного самоуправле- ния [21], мониторинг дефектных норм [22], а также пути устранения правотворческих ошибок [23] .

В последнее время четко наметилось несколько тенденций систематизации в российском законодательстве. При этом общая концепция систематизации не регламентирована и можно рассуждать о формах, видах, содержании и иных ее элементах. Традиционно различают несколько видов систематизации законодательства: учет, инкорпорация, консолидация и кодификация. Мы полагаем, что на современном этапе кодификация норм права выступает наиболее эффективным видом обработки нормативного материала - она позволяет, качественно пересмотрев разнородные нормативные акты, издать единый документ.

Понятие «государственное управление» теперь [24] нормативно закреплено - это деятельность органов государственной власти по реализации своих полномочий в сфере социальноэкономического развития Российской Федерации и обеспечения национальной безопасности Российской Федерации. На федеральном уровне систематизация норм, направленных на регулирование различных стадий государственного управления, или уже проведена, или ведется.

Федеральный закон от 28 июня 2014 г. № 172-Ф3 «О стратегическом планировании в Российской Федерации» предлагает различать на этой стадии государственного управления целеполагание, прогнозирование, планирование и программирование, устанавливает основной срок стратегического планирования - 6 лет, виды документов, 
иные аспекты этой деятельности. Необходимо обеспечить парламентский контроль за подготовкой, принятием и согласованием документов стратегического планирования между собой.

Минюстом России был вынесен на общественное обсуждение с 26 декабря 2014 г. по 23 февраля 2015 г. [25] проект Федерального закона «О нормативных правовых актах в Российской Федерации». В проекте Закона большая часть содержания направлена на регулирование нормотворчества - стадии государственного управления, следующей за планированием. Разработчиком проекта Закона назван Минюст России, однако это доработанный вариант проекта, подготовленного сотрудниками Института законодательства и сравнительного правоведения при Правительстве Российской Федерации [26]. Факт разработки проекта Федерального закона «О нормативных правовых актах в Российской Федерации» следует безусловно поддержать, однако его концепция, структура и содержание требуют существенной переработки.

Стадия реализации права в государственном управлении связана, прежде всего, с правоприменением. Эта деятельность настолько разнопланова, что систематизация всех форм правоприменения вряд ли возможна. В то же время, правоприменительная деятельность судов частично систематизирована и ведется ее совершенствование (см. таблицу 2). В то же время анонсированный проект единого Гражданско-процессуального кодекса Российской Федерации пока не принят и очевидно, что необходимо интенси- фицировать работу по его доработке, принятию и введению в действие как в судах общей юрисдикции, так и в арбитражных судах в целях обеспечения единства правоприменения.

Минэкономразвития России разработан проект Федерального закона «Об основах государственного и муниципального контроля и надзора в Российской Федерации» (далее - проект Закона). Соглашаясь с заявленными целями разработки проекта Закона, следует признать попытку систематизации в одном нормативном правовом акте всех применяемых в Российской Федерации форм государственного и муниципального контроля и надзора в целом неудачной в силу следующих причин.

Название проекта Закона не соответствует его содержанию, поскольку из предмета регулирования оказались исключены 11 форм контрольно-надзорной деятельности (ч. 2 ст. 1 проекта Закона), а объект контрольно-надзорной деятельности «сужен» только до сферы предпринимательской деятельности, осуществляемой физическими и юридическими лицами. При этом разработчиками, безусловно, проведена систематизация большого объема нормативного правового материала по вопросам осуществления государственного контроля за предпринимательской деятельностью, но тогда следовало внести поправки в Федеральный закон от 26 декабря 2008 г. № 294-Ф3 «О защите прав юридических лиц и индивидуальных предпринимателей при осуществлении государственного контроля (надзора) и муниципального контроля»). 
На наш взгляд, одним из показателей качества закона выступает полнота правового регулирования и тщательно продуманная система отсылочных норм, которые к моменту принятия базового документа должны быть обеспечены либо модельными (типовыми) актами, либо проработаны концептуально. Указанный проект Закона содержит недопустимо большое количество отсылочных норм (более 250 , из которых более 60 с формулировкой «установленных законодательством Российской Федерации»), что «размывает» содержание проекта Закона. Причем очевидно, что некоторые отсылки предполагают разработку качественно новых для российской правовой системы правовых средств (например, создать новые государственные информационные системы), что многократно усложняет понимание предлагаемого механизма государственного и муниципального контроля и надзора.

В главе 4 проекта Закона предлагается ввести крайне запутанную систему оценки рисков с использованием: категорий, групп, критериев, профилей, индикаторов, постоянных и переменных факторов (источников), объектных, субъектных и смешанных моделей.

Принятие проекта Закона в данной редакции повлечет не сокращение (ст. 131 проекта Закона не устраняет множество действующих нормативных правовых актов), а многократное увеличение количества нормативных правовых актов, поскольку ст. 30 проекта Закона предполагает разработку каждым субъектом контроля по ка- ждому виду контрольно-надзорной деятельности специального административного регламента, каждый из которых является по своей природе нормативным правовым актом.

Одним из индикаторов (показателей, критериев) культуры законотворчества должна выступать оценка эффективности качества государственного управления. В свою очередь, среди них ведущее место занимает система правового регулирования мониторинга правоприменения - на федеральном уровне принято Положение о мониторинге правоприменения в Российской Федерации [27], утверждена Методика осуществления мониторинга правоприменения в Российской Федерации [28], осуществляется уже шестой план мониторинга правоприменения в Российской Федерации, опубликованы доклады Правительства Российской Федерации о результатах мониторинга правоприменения в Российской Федерации за 2011-2014 годы.

Полагаем, результаты мониторинга правоприменения должны стать предметом первоочередных законопроектов, рассматриваемых Государственной Думой Российской Федерации, особенно по линии исполнения решений Конституционного Суда Российской Федерации и Европейского суда по правам человека. Считаем недопустимым ситуацию, при которой отдельные нормы законодательных актов признаны недействующими как противоречащие Конституции Российской Федерации и актам международного права, но остаются в законах, не пройдя предусмотренную процедуру отмены (замены). 
Систематизация может осуществляться не только по уровням публичного управления, но и по предмету правового регулирования. Например, коррупция названа одной из основных угроз государственной и общественной безопасности[29], системной угрозой безопасности Российской Федерации. Противодействие коррупции предложено понимать как деятельность федеральных органов государственной власти, органов государственной власти субъектов Российской Федерации, органов местного самоуправления, институтов гражданского общества, организаций и физических лиц в пределах их полномочий:

a) по предупреждению коррупции, в том числе по выявлению и последующему устранению причин коррупции (профилактика коррупции);

б) по выявлению, предупреждению, пресечению, раскрытию и расследованию коррупционных правонарушений (борьба с коррупцией);

в) по минимизации и (или) ликвидации последствий коррупционных правонарушений.

Формирование механизма противодействия коррупции в Российской Федерации осуществляется с учетом мирового опыта, отраженного в международных актах. Следует заметить, что универсальной модели построения механизма противодействия коррупции не существует. В международных актах названы и в общих чертах охарактеризованы наиболее эффективные меры противодействия коррупции. Отсюда логичен вопрос: как каждая страна построит механизм противодействия коррупции, адаптировав кон- кретные меры под уникальные условия правовой системы и механизма государства, как организует их внедрение?

Особенности каждой меры профилактики и борьбы с коррупцией раскрыты в специальных нормативных правовых актах: федеральных законах, указах Президента Российской Федерации, постановлениях Правительства Российской Федерации. Очевидно, что меры противодействия коррупции не могли быть внедрены одномоментно, а вводились в соответствии с национальными планами противодействия коррупции, каждый из которых рассчитан для реализации в течение двух лет.

Внедрение мер противодействия коррупции сопровождается (правда, не по всем мерам и не всегда своевременно) информативными официальными разъяснениями по вопросам применения отдельных мер противодействия коррупции, которые разрабатывают специально уполномоченные на то органы - Президиум Совета при Президенте Российской Федерации по противодействию коррупции и Минтруд России. Некоторые рекомендации с учетом практики правоприменения усовершенствованы (версия 2.0[30] и даже 3.0[31]), успешен опыт внедрения специального программного обеспечения [32].

В то же время вопросы правовой регламентации по минимизации и (или) ликвидации последствий коррупционных правонарушений остались без должного внимания. В частности, в Федеральном законе от 25 декабря 2008 г. № 273-Ф3 «О противодействии коррупции» такое направление противодействия коррупции обозначено, но 
не раскрыто. Впрочем, не конкретизирован и перечень коррупционных правонарушений, в том числе коррупционных преступлений. Данный пробел восполняется путем подзаконного регулирования, в частности принятием Перечня 23 преступлений коррупционной направленности, утвержденного совместным указанием Генеральной Прокуратуры Российской Федерации и МВД России. Однако очевидно, что данный документ не является по своей природе нормативным правовым актом и не может рассматриваться как официальный перечень коррупционных преступлений. Следовательно, выстраивание механизма противодействия коррупции в современной России осуществляется в отношении не конкретизированного объекта защиты.

В настоящее время в России наметилась тенденция к увеличению доли непосредственного участия граждан в государственном и муниципальном управлении, в том числе в правотворческой деятельности. Одной из стадий правотворчества теперь можно с уверенностью назвать общественное обсуждение проектов нормативных правовых актов.
Отметим активизацию исследований, посвященных теме общественного обсуждения проектов нормативных правовых актов, но нельзя сказать, что это исключительно современная правовая технология, поскольку эта тема поднималась и в досоветской литературе[33], и в советское время[34]. Интересно, что процедуры и результаты общественных обсуждений проектов конкретных нормативных правовых актов стали самостоятельным жанром научных публикаций.

Обычно вопросы общественного обсуждения проектов нормативных правовых актов рассматриваются как институт непосредственной демократии специалистами в области конституционного права и муниципального права, в то время как в теории права данная проблематика затрагивается фрагментарно. Например, в муниципальном праве отмечается, что сложился межотраслевой правовой институт, регулирующий общественные отношения, связанные с обсуждением проектов муниципальных правовых актов и вопросов местного значения с участием жителей муниципального образования[35].

\section{Библиография:}

1. Утверждены Указом Президента Российской Федерации от 24 декабря 2014 г. № 808 // Собрание законодательства РФ. 2014. № 52, ч. 1, ст. 7753.

2. Новейший словарь иностранных слов и выражений. М.: Современный литератор, 2003. С. 453.

3. Современный толковый словарь русского языка. СПб.: «Норинт», 2004. С. 306.

4. Новейший словарь иностранных слов и выражений. М.: Современный литератор, 2003. С. 453.

5. Современный толковый словарь русского языка. СПб.: «Норинт», 2004. С. 306. 
6. Правотворческие ошибки: понятие, виды, практика и техника устранения в постсоветских государствах: материалы Международного научно-практического круглого стола (29-30 мая 2008 года) / под ред. В.М. Баранова, И.М. Мацкевича. М.: Проспект, 2009. 1120 с.

7. Юридическая техника. 2016. № 10: Законотворческая, интерпретационная, правоприменительная техника в контексте культуры и межкультурной коммуникации. 746 с.

8. Калинин А.Ю. Правообразование в России: понятийно-категориальный и структурно-функциональный состав (историко-теоретическое исследование): автореф. дис. ... д-ра юрид. наук. СПб., 2010. С. 54.

9. Лашков А.С. Правотворческие ошибки (проблемы теории и практики): автореф. дис. ... канд. юрид. наук. СПб., 1999; Каменева Е.Н. Дефектные акты органов законодательной и исполнительной власти: автореф. дис. ... канд. юрид. наук. М., 2002; Москалькова Т.Н., Черников В.В. Нормотворчество: научно-практическое пособие. М., 2010. С. 336-341; Малько А.В. Правотворческие ошибки и правотворческая политика // Правотворческая политика в современной России: курс лекций / под ред. А.В. Малько. Саратов: Изд-во ФГБОУ ВПО «Саратовская государственная юридическая академия», 2013. C. 290-306.

10. Лукашева А.В. Законотворческие ошибки // Гражданин и право. 2000. № 3; Надеев Р. Законотворческие ошибки // Российская юстиция. 2001. № 5. С. 20-22; Мательский А. Типичные ошибки в нормотворческой деятельности // Юстиция Беларуси. 2003. № 6. С. 24-27; № 4. С. 19-22; Чинарян Е.О. Понятие и общая характеристика законотворческой ошибки // Современное право. 2010. № 9. С. 22-26.

11. Тихомиров Ю.А. Юридическое проектирование: критерии и ошибки // Журнал российского права. 2008. № 2. С. 90.

12. Бахвалов С.В. Опубликование нормативных правовых актов: типичные ошибки, пути их преодоления // Правотворческие ошибки: понятие, виды, практика и техника устранения в постсоветских государствах: материалы Международного научно-практического круглого стола (29-30 мая 2008 года) / Под ред. В.М. Баранова, И.М. Мацкевича. М.: Проспект, 2009. С. 391-401.

13. Игнатьева И.А. Законотворческие ошибки и иные недостатки действующего экологического законодательства и причины их появления // Экологическое право. 2002. № 1; Жильцов М.А. Дефекты трудового права. Екатеринбург, 2010 .

14. Пишина С.Г. Правоинтерпретационные ошибки. Проблемы теории и практики: дис. ... канд. юрид. наук. Н. Новгород, 2000; Иванова О.М. Интерпретационная деятельность как средство восполнения пробелов, обусловленных правотворческими ошибками // Правотворческие ошибки: понятие, виды, практика и техника устранения в постсоветских государствах: материалы Международного научно-практического круглого стола (29-30 мая 2008 года) 
/ под ред. В.М. Баранова, И.М. Мацкевича. М.: Проспект, 2009. С. 621-364, Никитин С.В. Проблемы судебного оспаривания дефектных правовых актов, содержащих интерпретационные нормы // Российское правосудие. 2016. № 3 (119). С. 37-46.

15. Мурсалимов К.Р. Правоприменительные ошибки. Проблемы теории: автореф. дис. ... канд. юрид. наук. Н. Новгород, 2000. С. 67.

16. Акимов В.И. Понятие пробела в праве // Правоведение. 1969. № 3; Лазарев В.В. Пробелы в праве (Вопросы понятия пробелов и критика теории беспробельности права). Казань, 1969; Пиголкин А.С. Обнаружение и преодоление пробелов права // Советское государство и право. 1970. № 3. С. 49-57; Забигайло В.К. Проблема «пробелов в праве»: К критике буржуазной теории. Киев, 1974; Панасюк О.С. Пробелы в праве и способы их преодоления и устранения: автореф. дис. ... канд. юрид. наук. Ставрополь, 2012.

17. Тихомиров Ю.А. Юридическая коллизия. М., 1994; Лаврентьев А.Р. Коллизии института юридической ответственности: автореф. дис. ... канд. юрид. наук. Н. Новгород, 1999. С. 32.

18. Мушинский М.А. Проблемы диагностики правотворческих дефектов: научно-практическое пособие. Иркутск, 2009. С. 99.

19. Чувакова Л.А. Причины и условия ошибочной юридической деятельности (проблемы методологии): автореф. дис. ... канд. юрид. наук. Н. Новгород, 2003; Кибак И.А. Психологические ошибки в законотворческой деятельности // Вестник академии МВД Республики Беларусь. 2006. № 1.

20. Гущев М.Е., Муравьев И.А. Юридический дефект как общеправовой феномен: учебное пособие / под ред. В.М. Баранова. Н. Новгород, 2006; Мушинский M.А. Проблемы диагностики правотворческих дефектов: научно-практическое пособие. Иркутск: Институт законодательства и правовой информации им. М.М. Сперанского; Фонд «Право и Демократия», 2009; Муругина В.В. Дефектность юридических фактов как негативная черта правовой системы: автореф. дис. ... канд. юрид. наук. Саратов, 2010; Зуев О.М. Юридически дефектные нормативные правовые акты в системе источников права: автореф. дис. ... канд. юрид. наук. М., 2011.

21. Карташов В.Н. Ошибочная юридическая деятельность органов местного самоуправления: (некоторые методологические, теоретические и практически - прикладные аспекты проблемы) / В.Н. Карташов, Н.В. Вантеева. Ярославль, 2010; Кисличенко Е.И. Дефекты законодательства субъектов Российской Федерации в сфере местного самоуправления: (на примере Республики Марий-Эл): автореф. дис. ... канд. юрид. наук. Казань, 2012.

22. Баранов В.М. Мониторинг дефектности нормативных правовых актов / B.М. Баранов, М.А. Мушинский // Юридическая наука и практика: Вестник Нижегородской академии МВД России. 2011. № 1 (14). С. 79-88.

23. Осипов М.Ю. Роль правотворчества в профилактике ошибок в правовом регулировании // Ленинградский юридический журнал. 2009. № 4. С. 44-49; 
Морозова Л.А. Правотворческие ошибки и процессуальные средства их устранения // Государство и право. 2010. № 1. С. 5-11; Тихонравов Е.Ю. Способы восполнения пробелов в законодательстве: вопросы теории и истории: автореф. дис. ... канд. юрид. наук. М., 2013; Кузнецова Е.В. Выявление, преодоление и устранение законодательных пробелов органами конституционной юстиции в Российской Федерации: автореф. дис. ... канд. юрид. наук. Екатеринбург, 2015.

24. Пункт 2 ст. 3 Федерального закона от 28 июня 2014 г. № 172-Ф3 «О стратегическом планировании в Российской Федерации».

25. URL: http://regulation.gov.ru/project/21982.htm1?point=view project\&stage $=2 \&$ stage_id $=15453$

26. Никифоров М.В. Субъекты административного нормотворчества: монография. Н. Новгород: Нижегородская правовая академия, 2012.

27. О мониторинге правоприменения в Российской Федерации: указ Президента Российской Федерации от 20 мая 2011 г. № 657.

28. Об утверждении методики осуществления мониторинга правоприменения в Российской Федерации: постановление Правительства Российской Федерации от 19 августа 2011 г. № 694.

29. О Стратегии национальной безопасности Российской Федерации: указ Президента Российской Федерации от 31 декабря 2015 г. № 683. URL: http://www. pravo.gov.ru (дата обращения: 31.12.2015).

30. О требованиях к размещению и наполнению подразделов, посвященных вопросам противодействия коррупции, официальных сайтов федеральных государственных органов, Центрального банка Российской Федерации, Пенсионного фонда Российской Федерации, Фонда социального страхования Российской Федерации, Федерального фонда обязательного медицинского страхования, государственных корпораций (компаний), иных организаций, созданных на основании федеральных законов, и требованиях к должностям, замещение которых влечет за собой размещение сведений о доходах, расходах, об имуществе и обязательствах имущественного характера: приказ Минтруда России от 7 октября 2013 г. № 530н; Методические рекомендации по проведению оценки коррупционных рисков, возникающих при реализации функций: письмо Минтруда России от 25 декабря 2014 г. № $18-0 / 10 / \mathrm{B}-8980$.

31. Методические рекомендации по организации ротации федеральных государственных гражданских служащих.

32. Специальное программное обеспечение «Справки БК» (версия 2.1.0.0), информационные материалы по заполнению справок о доходах, расходах, об имуществе и обязательствах имущественного характера размещены для бесплатного использования на сайте Совета при Президенте Российской Федерации по противодействию коррупции. URL: http://kremlin.ru/structure/ councils\#institution-12 
33. Гольцендорф Ф. Роль общественного мнения в государственной жизни. СПб., 1881; Тард Габриэль. Общественное мнение и толпа. М., 1902; Хвостов В.М. Общественное мнение и политические партии. М., 1906; Чичерин Б.Н. О народном представительстве. СПб., 1866.

34. Горшков М.К. Общественное мнение: история и современность. М.: Политиздат, 1988; Сафаров Р.А. Общественное мнение в советской демократии. М., 1982; Уледов А.К. Общественное мнение советского общества. М., 1963.

35. Карагод Н.В. Преемственность и комплексность правового регулирования общественных отношений, связанных с обсуждением населением проектов правовых актов и вопросов местного значения // Конституционное и муниципальное право. 2010. № 8. С. 55.

\section{References (transliterated):}

1. Utverzhdeny Ukazom Prezidenta Rossiiskoi Federatsii ot 24 dekabrya $2014 \mathrm{~g}$. № 808 // Sobranie zakonodatel’stva RF. 2014. № 52, ch. 1, st. 7753.

2. Noveishii slovar' inostrannykh slov i vyrazhenii. M.: Sovremennyi literator, 2003. S. 453.

3. Sovremennyi tolkovyi slovar' russkogo yazyka. SPb.: «Norint», 2004. S. 306.

4. Noveishii slovar' inostrannykh slov i vyrazhenii. M.: Sovremennyi literator, 2003. S. 453.

5. Sovremennyi tolkovyi slovar' russkogo yazyka. SPb.: «Norint», 2004. S. 306.

6. Pravotvorcheskie oshibki: ponyatie, vidy, praktika i tekhnika ustraneniya v postsovetskikh gosudarstvakh: materialy Mezhdunarodnogo nauchno-prakticheskogo kruglogo stola (29-30 maya 2008 goda) / pod red. V.M. Baranova, I.M. Matskevicha. M.: Prospekt, 2009. 1120 s.

7. Yuridicheskaya tekhnika. 2016. № 10: Zakonotvorcheskaya, inter pretatsionnaya, pravoprimenitel'naya tekhnika v kontekste kul'tury i mezhkul'turnoi kommunikatsii. $746 \mathrm{~s}$.

8. Kalinin A.Yu. Pravoobrazovanie v Rossii: ponyatiino-kategorial'nyi i strukturnofunktsional'nyi sostav (istoriko-teoreticheskoe issledova-nie): avtoref. dis. ... d-ra yurid. nauk. SPb., 2010. S. 54.

9. Lashkov A.S. Pravotvorcheskie oshibki (problemy teorii i praktiki): avtoref. dis. ... kand. yurid. nauk. SPb., 1999; Kameneva E.N. Defektnye akty organov zakonodatel'noi i ispolnitel'noi vlasti: avtoref. dis. ... kand. yurid. nauk. M., 2002; Moskal'kova T.N., Chernikov V.V. Normotvorchestvo: nauchno-prakticheskoe posobie. M., 2010. S. 336-341; Mal'ko A.V. Pravotvorcheskie oshibki i pravotvorcheskaya politika // Pravotvorcheskaya politika v sovremennoi Rossii: kurs lektsii / pod red. A.V. Mal'ko. Saratov: Izd-vo FGBOU VPO «Saratovskaya gosudarstvennaya yuridicheskaya akademiya», 2013. S. 290-306.

10. Lukasheva A.V. Zakonotvorcheskie oshibki // Grazhdanin i pravo. 2000. № 3; Nadeev R. Zakonotvorcheskie oshibki // Rossiiskaya yustitsiya. 2001. № 5. S. 
20-22; Matel'skii A. Tipichnye oshibki v normotvorcheskoi deyatel'nosti // Yustitsiya Belarusi. 2003. № 6. S. 24-27; № 4. S. 19-22; Chinaryan E.O. Ponyatie i obshchaya kharakteristika zakonotvorcheskoi oshibki // Sovremennoe pravo. 2010. № 9. S. 22-26.

11. Tikhomirov Yu.A. Yuridicheskoe proektirovanie: kriterii i oshibki // Zhurnal rossiiskogo prava. 2008. № 2. S. 90.

12. Bakhvalov S.V. Opublikovanie normativnykh pravovykh aktov: tipichnye oshibki, puti ikh preodoleniya // Pravotvorcheskie oshibki: ponyatie, vidy, praktika i tekhnika ustraneniya v postsovetskikh gosudarstvakh: materialy Mezhdunarodnogo nauchno-prakticheskogo kruglogo stola (29-30 maya 2008 goda) / Pod red. V.M. Baranova, I.M. Matskevicha. M.: Prospekt, 2009. S. 391-401.

13. Ignat'eva I.A. Zakonotvorcheskie oshibki i inye nedostatki deistvuyu-shchego ekologicheskogo zakonodatel'stva i prichiny ikh poyavleniya // Ekologicheskoe pravo. 2002. № 1; Zhil’tsov M.A. Defekty trudovogo prava. Ekaterinburg, 2010.

14. Pishina S.G. Pravointerpretatsionnye oshibki. Problemy teorii i praktiki: dis. ... kand. yurid. nauk. N. Novgorod, 2000; Ivanova O.M. Inter-pretatsionnaya deyatel'nost' kak sredstvo vospolneniya probelov, obuslovlen-nykh pravotvorcheskimi oshibkami // Pravotvorcheskie oshibki: ponyatie, vidy, praktika i tekhnika ustraneniya v postsovetskikh gosudarstvakh: materialy Mezhdunarodnogo nauchno-prakticheskogo kruglogo stola (29-30 maya 2008 goda) / pod red. V.M. Baranova, I.M. Matskevicha. M.: Prospekt, 2009. S. 621-364, Nikitin S.V. Problemy sudebnogo osparivaniya defektnykh pravovykh aktov, soderzhashchikh interpretatsionnye normy // Rossiiskoe pravosudie. 2016. № 3 (119). S. 37-46.

15. Mursalimov K.R. Pravoprimenitel'nye oshibki. Problemy teorii: avtoref. dis. ... kand. yurid. nauk. N. Novgorod, 2000. S. 67.

16. Akimov V.I. Ponyatie probela v prave // Pravovedenie. 1969. № 3; Lazarev V.V. Probely v prave (Voprosy ponyatiya probelov i kritika teorii besprobel'nosti prava). Kazan', 1969; Pigolkin A.S. Obnaruzhenie i preodolenie probelov prava // Sovetskoe gosudarstvo i pravo. 1970. № 3. S. 49-57; Zabigailo V.K. Problema «probelov v prave»: K kritike burzhuaznoi teorii. Kiev, 1974; Panasyuk O.S. Probely v prave i sposoby ikh preodoleniya i ustraneniya: avtoref. dis. ... kand. yurid. nauk. Stavropol', 2012.

17. Tikhomirov Yu.A. Yuridicheskaya kolliziya. M., 1994; Lavrent'ev A.R. Kollizii instituta yuridicheskoi otvetstvennosti: avtoref. dis. ... kand. yurid. nauk. N. Novgorod, 1999. S. 32.

18. Mushinskii M.A. Problemy diagnostiki pravotvorcheskikh defektov: nauchnoprakticheskoe posobie. Irkutsk, 2009. S. 99.

19. Chuvakova L.A. Prichiny i usloviya oshibochnoi yuridicheskoi deyatel'nosti (problemy metodologii): avtoref. dis. ... kand. yurid. nauk. N. Novgorod, 2003; Kibak I.A. Psikhologicheskie oshibki v zakonotvorcheskoi deyatel'nosti // Vestnik akademii MVD Respubliki Belarus’. 2006. № 1. 
20. Gushchev M.E., Murav'ev I.A. Yuridicheskii defekt kak obshchepravovoi fenomen: uchebnoe posobie / pod red. V.M. Baranova. N. Novgorod, 2006; Mushinskii M.A. Problemy diagnostiki pravotvorcheskikh defektov: nauchno-prakticheskoe posobie. Irkutsk: Institut zakonodatel'stva i pravovoi informatsii im. M.M. Speranskogo; Fond «Pravo i Demokratiya», 2009; Murugina V.V. Defektnost' yuridicheskikh faktov kak negativnaya cherta pravovoi sistemy: avtoref. dis. ... kand. yurid. nauk. Saratov, 2010; Zuev O.M. Yuridicheski defektnye normativnye pravovye akty $\mathrm{v}$ sisteme istochnikov prava: avtoref. dis. ... kand. yurid. nauk. M., 2011.

21. Kartashov V.N. Oshibochnaya yuridicheskaya deyatel'nost' organov mestnogo samoupravleniya: (nekotorye metodologicheskie, teoreticheskie i prakticheski prikladnye aspekty problemy) / V.N. Kartashov, N.V. Vanteeva. Yaroslavl', 2010; Kislichenko E.I. Defekty zakonodatel'stva sub' 'ektov Rossiiskoi Federatsii v sfere mestnogo samoupravleniya: (na primere Respubliki Marii-El): avtoref. dis. ... kand. yurid. nauk. Kazan', 2012.

22. Baranov V.M. Monitoring defektnosti normativnykh pravovykh aktov / V.M. Baranov, M.A. Mushinskii // Yuridicheskaya nauka i praktika: Vestnik Nizhegorodskoi akademii MVD Rossii. 2011. № 1 (14). S. 79-88.

23. Osipov M.Yu. Rol' pravotvorchestva v profilaktike oshibok v pravovom regulirovanii // Leningradskii yuridicheskii zhurnal. 2009. № 4. S. 44-49; Morozova L.A. Pravotvorcheskie oshibki i protsessual'nye sredstva ikh ustraneniya // Gosudarstvo i pravo. 2010. № 1. S. 5-11; Tikhonravov E.Yu. Sposoby vospolneniya probelov v zakonodatel'stve: voprosy teorii i istorii: avtoref. dis. ... kand. yurid. nauk. M., 2013; Kuznetsova E.V. Vyyavlenie, preodolenie i ustranenie zakonodatel'nykh probelov organami konstitutsionnoi yustitsii v Rossiiskoi Federatsii: avtoref. dis. ... kand. yurid. nauk. Ekaterinburg, 2015.

24. Punkt 2 st. 3 Federal'nogo zakona ot 28 iyunya 2014 g. № $172-F Z$ «O strategicheskom planirovanii v Rossiiskoi Federatsii».

25. URL: http://regulation.gov.ru/project/21982.htm1?point=view_ project\&stage $=2 \&$ stage_id $=15453$

26. Nikiforov M.V. Sub' 'ekty administrativnogo normotvorchestva: monografiya. N. Novgorod: Nizhegorodskaya pravovaya akademiya, 2012.

27. O monitoringe pravoprimeneniya v Rossiiskoi Federatsii: ukaz Prezidenta Rossiiskoi Federatsii ot 20 maya 2011 g. № 657.

28. Ob utverzhdenii metodiki osushchestvleniya monitoringa pravoprimeneniya $\mathrm{v}$ Rossiiskoi Federatsii: postanovlenie Pravitel'stva Rossiiskoi Federatsii ot 19 avgusta 2011 g. № 694.

29. O Strategii natsional'noi bezopasnosti Rossiiskoi Federatsii: ukaz Prezidenta Rossiiskoi Federatsii ot 31dekabrya 2015 g. № 683. URL: http://www.pravo.gov. ru (data obrashcheniya: 31.12.2015).

30. O trebovaniyakh $\mathrm{k}$ razmeshcheniyu i napolneniyu podrazdelov, posvyashchennykh voprosam protivodeistviya korruptsii, ofitsial'nykh saitov federal'nykh 
gosudarstvennykh organov, Tsentral'nogo banka Rossiiskoi Federatsii, Pensionnogo fonda Rossiiskoi Federatsii, Fonda sotsial'nogo strakhovaniya Rossiiskoi Federatsii, Federal'nogo fonda obyazatel'nogo meditsinskogo strakhovaniya, gosudarstvennykh korporatsii (kompanii), inykh organizatsii, sozdannykh na osnovanii federal'nykh zakonov, i trebovaniyakh k dolzhnostyam, zameshchenie kotorykh vlechet za soboi razmeshchenie svedenii o dokhodakh, raskhodakh, ob imushchestve i obyazatel'stvakh imushchestvennogo kharaktera: prikaz Mintruda Rossii ot 7 oktyabrya 2013 g. № 530n; Metodicheskie rekomendatsii po provedeniyu otsenki korruptsionnykh riskov, voznikayushchikh pri realizatsii funktsii: pis’mo Mintruda Rossii ot 25 dekabrya 2014 g. № 18-0/10/V-8980.

31. Metodicheskie rekomendatsii po organizatsii rotatsii federal'nykh gosudarstvennykh grazhdanskikh sluzhashchikh.

32. Spetsial'noe programmnoe obespechenie «Spravki BK» (versiya 2.1.0.0), informatsionnye materialy po zapolneniyu spravok o dokhodakh, raskhodakh, ob imushchestve i obyazatel'stvakh imushchestvennogo kharaktera razmeshcheny dlya besplatnogo ispol'zovaniya na saite Soveta pri Prezidente Rossiiskoi Federatsii po protivodeistviyu korruptsii. URL: http://kremlin.ru/structure/ councils\#institution-12

33. Gol'tsendorf F. Rol' obshchestvennogo mneniya v gosudarstvennoi zhizni. SPb., 1881; Tard Gabriel'. Obshchestvennoe mnenie i tolpa. M., 1902; Khvostov V.M. Obshchestvennoe mnenie i politicheskie partii. M., 1906; Chicherin B.N. O narodnom predstavitel'stve. SPb., 1866.

34. Gorshkov M.K. Obshchestvennoe mnenie: istoriya i sovremennost'. M.: Politizdat, 1988; Safarov R.A. Obshchestvennoe mnenie v sovetskoi demokratii. M., 1982; Uledov A.K. Obshchestvennoe mnenie sovetskogo obshchestva. M., 1963.

35. Karagod N.V. Preemstvennost' i kompleksnost' pravovogo regulirovaniya obshchestvennykh otnoshenii, svyazannykh s obsuzhdeniem naseleniem proektov pravovykh aktov i voprosov mestnogo znacheniya// Konstitutsionnoe i munitsipal'noe pravo. 2010. № 8. S. 55. 